\title{
AS CONTRIBUIÇÕES DO PNAIC PARA A ALFABETIZAÇÃO MATEMÁTICA: UM ESTUDO DE CASO
}

\author{
JAQUELINE DE MORAIS COSTA* \\ NILCEIA APARECIDA MACIEL PINHEIRO**
}

PNAIC CONTRIBUTIONS TO MATHEMATICAL LITERACY: A CASE STUDY

\section{RESUMO}

Este estudo objetivou analisar as contribuições da formação continuada em matemática do Pacto Nacional Pela Alfabetização na Idade Certa (PNAIC) para a prática pedagógica dos professores alfabetizadores do município de Ponta Grossa. Para isso, buscou-se nas bases teóricas a compreensão do tema formação continuada em matemática de professores dos anos iniciais, com referência, principalmente, nos escritos de Nóvoa (1992, 2009), Sacristán e Goméz (1998), Serrazina (2010, 2012,) e Tardif (2012). Como metodologia, adotou-se a perspectiva estudo de caso. A pesquisa foi realizada com dezesseis professores alfabetizadores do município analisado. Os resultados demonstram contribuições significativas do PNAIC, identificadas no desenvolvimento de saberes disciplinares dos professores, bem como na compreensão de conceitos inerentes ao ensino da matemática no Ciclo de Alfabetização, assumidas nas práticas docentes. Além disso, mostraram também lacunas como fragilidade no acompanhamento do processo de planejar, o não envolvimento da escola em seu contexto meso e a desconsideração de outras variáveis que interferem diretamente no trabalho docente.

Palavras-chave: PNAIC. Formação continuada. Ensino de matemática. Anos iniciais.

\section{ABSTRACT}

This study analyzed the contributions of the continuing education in mathematics of the "Pacto Nacional Pela Alfabetização na Idade Certa" (PNAIC) to the pedagogical practice of literacy teachers in the municipality of Ponta Grossa. In order to do So, we sought studies on the theme Continuing Education of Mathematics Early Years Teacher, mainly based on the writings of Nóvoa (1992, 2009), Sacristán and Goméz (1998), Serrazina (2010, 2012) and Tardif (2012). As a methodological proposal, we adopted the case study. The research was carried out with sixteen literacy teachers in the analyzed city. The results demonstrate significant contributions of PNAIC, identified in the development of disciplinary knowledge of teachers, as in the understanding of concepts inherent to Mathematics Teaching in the literacy cycle, assumed in the teaching practices. In addition, the results also showed gaps, such as fragility in the follow-up of the planning process, non-involvement of the school in its meso context, and disregard for other variables that directly interfere in the teacher's job.

Keywords: PNAIC. Continuing education. Mathematics teaching. Early years.

\footnotetext{
* Doutora em Ensino de Ciência e Tecnologia. Universidade Estadual de Ponta Grossa. Faculdade Sagrada Família. j.moraiscosta@hotmail.com. ORCID: https://orcid.org/0000-0003-2161-5509

** Doutora em Educação Científica e Tecnológica. Universidade Tecnológica Federal do Paraná. nil-ceia@utfpr.edu.br. ORCID: https://orcid.org/ 0000-0003-3313-1472
} 


\section{INTRODUÇÃO}

Analisar a prática pedagógica exige um esforço para a compreensão acerca do que motiva as escolhas e as posturas do professor frente ao ensino. Nesse sentido, Tardif (2012) explica que a ação docente é, na verdade, fruto dos reflexos de sua consciência profissional, caracterizada pelos conhecimentos possíveis de serem explicitados e também de suas experiências, consideradas as vivências pessoais, escolares e profissionais e sua consciência sobre a prática, o que denota o fazer consciente.

Porém, tais reflexões não amadurecem com o tempo, como se fossem inatas. Requerem momentos que possibilitem análises e autoconhecimento, o que fortemente tem sido promovido pela formação contínua.

Com base neste pressuposto, este artigo tem como proposta apresentar os resultados da tese intitulada "Formação continuada para professores alfabetizadores: um estudo de caso sobre as contribuições do PNAIC no município de Ponta Grossa", vinculada ao Programa de Pós-Graduação em Ensino de Ciência e Tecnologia (PPGECT), pela Universidade Tecnológica Federal do Paraná (UTFPR). 0 estudo partiu da seguinte problemática: "quais as contribuições da formação continuada em matemática do PNAIC para a prática pedagógica dos professores alfabetizadores do município de Ponta Grossa/PR?"

0 PNAIC é colocado como um compromisso assumido entre o Ministério da educação e as secretarias estaduais, distritais e municipais de educação, do Distrito Federal, dos estados e municípios "de alfabetizar as crianças até, no máximo, os oito anos de idade, ao final do $3^{\circ}$ ano do ensino fundamental," (BRASIL, 2012, art. 10). Esta pactuação envolve ações nos seguintes eixos: Formação Continuada; Materiais Didáticos; Avaliação e; Gestão, Controle Social e Mobilização.

0 primeiro eixo, da formação, foco de análise deste artigo, é destinado a professores alfabetizadores e orientadores de estudo, com o objetivo de alfabetizar as crianças na língua portuguesa e na matemática durante $01^{\circ}$ ciclo de formação dos Anos Iniciais do Ensino Fundamental, em que a criança tem entre 06 (seis) e 08 (oito) anos de idade. Posteriormente, este eixo teve sua temática ampliada, inserindo as demais áreas do conhecimento, dentro de uma abordagem interdisciplinar.

Tendo como objetivo geral analisar quais as contribuições da formação continuada em matemática do PNAIC para a prática pedagógica dos professores alfabetizadores do município de Ponta Grossa/PR, a possibilidade de conhecer a história de formação das professoras que foram sujeitos desta pesquisa, possibilitou compreender o que move o tacto pedagógico (NÓVOA, 2009), reconhecido como condução didática para o encaminhamento da prática docente.

A metodologia adotada para esta pesquisa foi o estudo de caso, com base em Yin (2001). Como procedimentos, foram observados os encontros de formação do PNAIC, etapa da matemática, os quais totalizaram 11 momentos com um grupo de formação, composto por 18 professores, ocorrido no ano de 2014.

Para coleta de dados, foram empregados como instrumentos: entrevistas semiestruturadas, realizadas por meio de visitas as escolas dos pesquisados; entrevistas não estruturadas, ocorridas durante os encontros de formação; questionários, sendo aplicado um diagnóstico no primeiro dia de formação e outro de avaliação no último encontro; mais diário de bordo, para registro das observações do pesquisador.

Empregou-se como método de verificação dos resultados a análise textual discursiva, com base em Roque e Morais (2007), que possibilitou como categorização: "Contribuições do PNAIC: análise do discurso dos professores" e "Análises do modelo de formação do PNAIC: da visão dos professores ao diálogo com os autores". Porém, neste trabalho, será apresentado os resultados da 
primeira categoria, a qual se divide em: a relação do professor de Anos Iniciais com a matemática, ao examinar as habilidades, dificuldades, frustrações e superações com a área da matemática, considerando a construção dos saberes disciplinares e curriculares durante a trajetória do PNAIC; métodos e recursos para ensino, analisando os como e quais as ferramentas didáticas se ensina matemática e a evolução do processo de ensino no decorrer da formação do PNAIC e; planejamento das aulas de matemática, identificando como o professor prepara as suas aulas e verificados os encaminhamentos a partir do PNAIC.

\section{FORMAÇÃO CONTINUADA E SABERES DOCENTES: CONTRIBUIÇÕES PARA A PRÁTICA PEDAGÓGICA DE PROFESSORES QUE ENSINAM MATEMÁTICA NOS ANOS INICIAIS}

0 desenvolvimento de uma carreira docente, a qual começa pelo curso de formação inicial, perpassa por um processo contínuo, marcado pela construção de saberes, alicerçados nos conhecimentos técnicos (área que se ensina) e pedagógicos (como se ensina), bem como nas experiências profissionais vivenciadas. Isso indica que a prática pedagógica é capaz de incluir, retificar ou transformar os saberes docentes.

Considerando a perspectiva de formação no campo da docência, Chantraine-Demally (1995), Garcia (1995), Passos (2006) e Imbérnon (2011) salientam que esta necessita ser um processo contínuo, pontuando o porquê desta premissa.

0 objetivo de toda formação continuada é, segundo Chantraine-Demally (1995), a melhora do ensino. Para alcançar esse objetivo, Garcia (1995) afirma que a formação do professor deve ser compreendida como uma cadeia corrente de aperfeiçoamento, a qual começa pela formação inicial e, por isso, a importância de concebê-la como processo contínuo. Passos (2006, p. 195) traz importantes considerações sobre essa discussão, ao afirmar que "a formação contínua, portanto, é um fenômeno que ocorre ao longo de toda a vida e que acontece de modo integrado às práticas sociais e às cotidianas escolares de cada um, ganhando intensidade e relevância em algumas delas".

Para Nóvoa (2009), a formação do professor, após seu curso inicial, deverá vislumbrar a ação nas seguintes frentes: práticas, que se refere à práxis pedagógica, centrando os estudos na aprendizagem dos alunos por meio de casos concretos, tendo como referência o trabalho escolar; profissão, por meio da aquisição de uma cultura profissional, concedendo aos professores mais experientes um papel central na formação dos mais jovens; pessoa, ou seja, dimensões pessoais da profissão docente, trabalhando essa capacidade de relação e de comunicação que define o trato pedagógico; partilha, pela valorização do trabalho em equipe e 0 exercício coletivo da profissão, reforçando a importância dos projetos educativos da escola e; público, pelo princípio de responsabilidade social, favorecendo a comunicação pública e a participação profissional no espaço público da educação.

Ao se pesquisar sobre as contribuições que um processo de formação de professores surte em seu trabalho, busca-se aporte do autor Tadif (2000; 2012). 0 referido autor apresenta uma proposta de categorização dos saberes docentes, sendo eles: saberes da formação profissional, que são aqueles adquiridos nos períodos de formação, cujo foco é a ciência da educação e a ideologia pedagógica, mobilizadora dos saberes pedagógicos; saberes disciplinares, considerados os conhecimentos socialmente construídos e componentes da cultura, quase sempre, organizados em disciplinas (daí deriva sua nomenclatura); saberes curriculares considerados as formas de mobilização dos saberes disciplinares, considerando seus objetivos e métodos e saberes experienciais, que são construídos a partir da prática docente. 
Para Tardif (2012), esses saberes são provenientes de vários conhecimentos oriundos de diferentes fontes, sendo eles temporais, heterogêneos, variados, personalizados e situacionais, sendo seu objeto principal o ser humano.

Desta forma, pode-se concluir que os saberes docentes são construídos por um processo muito complexo, que envolve conhecimentos, experiências e compartilhamento destas vivências. Pode-se também verificar o quanto o contexto no qual a prática pedagógica se desenvolve influencia diretamente nos saberes destes professores. Por esse motivo, para o presente trabalho, é de extrema relevância refletir sobre os saberes do professor de Anos Iniciais.

Analisando a formação do professor de Anos Iniciais, identifica-se importantes especificidades, conforme aponta por Brzezinski (2008), principalmente considerando o caráter de sua atuação polivalente, tais como: conhecimento específico de cada área do conhecimento que necessita ensinar; saber pedagógico, que envolve questões didáticas, uso de tecnologias e reflexão sobre a prática educativa; saber cultural e político, necessário para compreensão e formação dos alunos sobre aspectos de sua cultura e compreensão da organização social-política e, por fim, saber transversal, que propicie 0 trabalho transdisciplinar, rompendo com as posturas tradicionais de ensino.

Ao se tratar pontualmente sobre 0 ensino de matemática nos Anos Iniciais do Ensino Fundamental, necessariamente, exige explanar sobre a atuação docente para este ensino, pois segundo Ponte e Serrazina (2004), certamente, a qualidade de ensino e aprendizagem em matemática é influenciada diretamente pelas práticas educativas geridas pelos professores.

Cunha (2010) explica que os dois elementos fundamentais para o trabalho docente com 0 ensino de matemática nos Anos Iniciais são o domínio do conteúdo e o domínio pedagógico do conteúdo, sendo que 0 conhecimento de conteúdo do professor dos Anos Iniciais não deve ficar restrito ao que se precisa ensinar. Já segundo Serrazina (2010), os conceitos que envolvem a educação matemática podem ser caracterizados como: conhecimento matemático do professor: saber aprofundado acerca dos conteúdos de matemática - capacidade de raciocínio matemático; conhecimento didático: adequar o conhecimento matemático ao ensino e; conhecimento curricular: currículo, objetivos, finalidades dos conteúdos - articula conteúdos e recursos a serem utilizados.

Sobre o tema Sarti (2012) alerta sobre a influência que a insegurança do professor em uma determinada área com certeza trará ao ensino, pois é natural que o docente evite tratar de um assunto que não domine. Neste mesmo aspecto, a autora Curi (2004) reflete que devido à fragilidade na formação inicial dos docentes, o currículo de matemática nos Anos Iniciais, considerando objetivos de formação, conteúdos e estratégias, acaba sendo definido por assessores técnicos, ou pior, pelo que se apresenta no livro didático.

Por isso, conforme explica Serrazina (2012), o professor precisar ter consciência de como e 0 que foi aprendido pelos alunos, para que as próximas atividades planejadas possam dar sequência ao aprendizado ou retomar pontos que ainda estão obscuros para os alunos. No caso de ocorrer a segunda possibilidade, sem que o professor possa desenvolver estratégias para que 0 aluno aprenda os conceitos anteriores, não é possível que este simplesmente ignore uma base necessária de conceitos e construa aprendizados posteriores. Isso exige a compreensão da avaliação como processo de acompanhamento e balizadora de ações futuras e não como finalizadora do planejamento.

Em síntese, a busca pelo processo de formação dos professores que atuam nos Anos Iniciais deve ser pautada na ação reflexiva do professor, preconizando a consciência, durante 0 ato educativo, do contexto, dos métodos adequados, da finalidade do que ensina e avaliação constante dos alunos para reconhecimento do processo de aprendizagem (SERRAZINA 2010). Sua reflexão 
é possível conforme o professor aprofunda seus conhecimentos matemáticos e didáticos, pois ao mesmo tempo em que compreende melhor os conceitos, pensará em estratégias para que estes se tornem compreensíveis aos alunos.

\section{OS DADOS DA PESQUISA E SEUS DESVELAMENTOS}

\section{OS PROFESSORES DOS ANOS INICIAIS E SUA RELAÇÃO COM A MATEMÁTICA}

A análise desta temática considerou a percepção dos professores de suas habilidades e dificuldades com a área de matemática, considerando o processo de formação. Antes de iniciar as atividades de formação, foi perguntado aos docentes no questionário diagnóstico sobre sua dificuldade (ou não) no trabalho com matemática. Como resultado, obteve-se que 47,5\% dos professores afirmam sentir muita dificuldade ou dificuldade no trabalho com matemática.

Para investigar as razões que levam à dificuldade, foi solicitado aos professores indicarem, em uma escala de 1 (para nada interfere) à 5 (para muito interfere), quais condicionantes poderiam estar afetando 0 trabalho em sala de aula. A partir das respostas indicadas, foi realizada sobre cada questão uma média simples do valor atribuído pelos professores, cujo resultado expressou o ponto de vista do grupo. ${ }^{1}$

Assim, as razões que levam a essa dificuldade são ilustradas no gráfico 1 :

Gráfico 1 - Condicionantes que Levam a Dificuldade para o Ensino da Matemática para Professores Alfabetizadores (PONTA GROSSA/ PR, 2014)



Fonte: A autora.

1 Este mesmo procedimento foi realizado nas demais questões que envolvem escalas de intensidade. 
Conforme apresentado no gráfico 1, na percepção dos professores pesquisados, entre as razões que levam a essa dificuldade, foram apontados como principais fatores: 0 número excessivo de alunos em sala de aula, falta de abordagem do tema em cursos de formação continuada, pouca afinidade do docente com a área e os conhecimentos prévios dos alunos, sendo apresentada a média de cada um dos itens indicados.

Buscando verificar melhor o perfil dos professores que reconhecem dificuldade com matemática, foram isolados os dados do questionário diagnóstico dos pesquisados que indicaram sentir muita dificuldade ou dificuldade no trabalho com matemática, que incidiu em $47 \%$ da amostra. Identificou-se neste grupo que apenas $25 \%$ indicaram a realização de cursos de formação continuada na área do ensino da matemática. Foi então realizada uma apuração entre os professores que indicam possuir pouca ou nenhuma dificuldade no trabalho com matemática, que representou $41 \%$ da amostra. A pesquisa identificou que $66,7 \%$ dos professores pesquisados, que indicaram não sentir ou sentir pouca dificuldade no trabalho com matemática, realizaram cursos de formação continuada na área.

Esses dados reforçam que saberes provenientes da formação profissional para o magistério, explicada por Tardif (2012), não são suficientes para a ação docente. Por isso, é compreensível a identificação de que professores que mais investiram em formação continuada demonstram sentir menos dificuldade frente ao ensino de matemática. A partir da constatação desta informação, tornou-se mais pertinente acompanhar o programa PNAIC com vistas a verificar suas contribuições na prática pedagógica.

A fragilidade no trato com 0 ensino de matemática se mostrou presente em outros momentos nos quais a pesquisa foi realizada. Discutindo 0 assunto no grupo de formação, ocorreram relatos sobre essa dificuldade por pelo menos $37,5 \%$ dos professores, ilustradas na voz da professora P06:

Eu tenho um pouco de dificuldade, não nego. Só que assim, até um terceiro ano eu não vejo dificuldade, eu já sinto mais dificuldade quando já vai para quarto, quinto ano que amplia, sabe. Mas até o terceiro ano eu não vejo dificuldade, porque é a base (P06).

Neste caso, apesar de não sentirem dificuldade no Ciclo de Alfabetização, nem sempre as professoras dominam os conhecimentos matemáticos dos Anos Iniciais. Essa verificação remete aos escritos de Serrazina (2012), os quais colocam que um dos condicionantes necessários para 0 trato com 0 ensino de matemática é que o conhecimento do professor não esteja limitado apenas ao conteúdo a ser ensinado. Na pesquisa desenvolvida, verificou-se um saber curricular e disciplinar (TARDIF, 2012) bastante limitado.

Outro ponto interessante é a ênfase dada aos professores em determinada área, o que pode estar associado à complexidade vista pelo professor quando 0 assunto é matemática. Esta situação foi exposta por pelo menos $37,5 \%$ do público pesquisado, os quais afirmam enfatizar mais o português. Entre os motivos, justificam por compreender que a alfabetização é mais importante, que leitura possibilita apoio para resolver problemas de matemática ou por maior afeição do docente com a área, conforme já alertava Sarti (2012). A fala da professora P04 representa esta posição:

Bom, primeiro eu acho que pela alfabetização, se preocupa primeiro em eles aprender a ler e a escrever, até porque a matemática também precisa da leitura, 
da escrita, da compreensão. E segundo porque eu sou da área de Letras. Acho que isso também contribui um pouco (P04).

0 enfoque no ensino da língua portuguesa negligencia um dos pontos primordiais da polivalência: a interdisciplinaridade (CURI, 2004). A visão das professoras mostra que não se reconhece que 0 trabalho de forma interdisciplinar completaria o processo de letramento do aluno, pois 0 a aprendizagem é vista ainda como conhecimentos separados em disciplinas.

Outras alfabetizadoras remetem que a dificuldade que sentem influencia em suas práticas, conforme relato de $37,5 \%$ dos professores pesquisados. 0 depoimento da professora P16 exemplifica essa preocupante constatação:

[...] eu acho que aí eu já não fui tão estimulada. Eu acho que a partir daí eu comecei a me interessar mais na área de português. É onde eu me identifico mais hoje também, sempre. Na questão das minhas aulas também (P16).

Tais asserções confirmam as colocações de Curi (2004), Ponte e Serrazina (2004) e Cunha (2010), quando afirmam que a precariedade na formação do professor acaba interferindo nas suas opções sobre 0 que e como ensinar.

No decorrer do processo de formação e com as visitas realizadas nas escolas das professoras, foram se desmistificando muitos dos motivos que geraram dificuldades dos professores no trabalho com matemática. As falas de $35,7 \%$ das entrevistadas demonstram a não concretização da aprendizagem dessas professoras em sua formação básica e a não superação destas no Ensino Superior.

Considerando a hipótese de que a formação continuada colabora para a construção dos conhecimentos do professor, trazendo mais segurança para o trabalho com matemática, buscou-se, nos instrumentos de coleta de dados, verificar como o professor considera o grau de dificuldade que sente no trabalho com matemática após a finalização do PNAIC.

Para isso, analisou-se no questionário de avaliação a indagação sobre a superação ou não de suas dificuldades a partir da participação no PNAIC. Como resposta, todos os participantes responderam que sim, sendo $64 \%$ dos professores como fortemente, $27 \%$ consideravelmente e $9 \%$ razoavelmente. Com isso, conclui-se que, na percepção das professoras pesquisadas, as dificuldades com o trabalho na área de matemática foram superadas, o que reforça o reconhecimento da importância de ações de formação continuada para a ação docente.

Outra importante consideração é a forma como esses professores encaram, após a formação, a área da matemática. Percebe-se que com o decorrer do PNAIC, ocorre uma visão diferenciada por $93,8 \%$ dos professores, expresso em diferentes momentos, exemplificado no depoimento da professora P07: "Eu não gostava de matemática. Agora já estou gostando mais depois do Pacto, porque eu trabalhava muito mecanicamente" (P07).

Em meio ao processo de formação, há identificação por parte desses professores das fragilidades do ensino e a construção de saberes da formação profissional (TARDIF, 2002), o que demonstra o processo contínuo de constituição da profissionalidade por meio da superação dos obstáculos e proposições para a mudança. 


\section{COMO OS PROFESSORES DE ANOS INICIAIS ENSINAM MATEMÁTICA: MÉTODOS E RECURSOS}

No decorrer dos encontros de formação do PNAIC, era perceptível no discurso dos participantes uma visão de ensino de matemática como uma atividade um tanto que penosa, devido à dificuldade que sentiam para lecioná-la. Isso mobilizou alguns dos professores para uma fuga, apresentando como argumento entender que 0 ensino da língua portuguesa seria mais importante, considerando que os alunos estavam no "Ciclo de Alfabetização". Essa postura mostra o não reconhecimento da premissa de que a alfabetização matemática é integrante desse processo, expressa em diferentes momentos da formação por $56,3 \%$ dos professores.

Presenciaram-se justificativas sobre os métodos de ensino empregados pelas professoras, como 0 número elevado de alunos em classe e a falta de tempo para o planejamento. Analisando os discursos e posturas dos professores frente às condições para o ensino da matemática, percebe-se certa vulnerabilidade no conhecimento dessa área por pelo menos $62,5 \%$ dos professores pesquisados, 0 que pode ser explicado por Serrazina (2010, p. 10) da seguinte forma: "0 professor precisa de 'desempacotar' a Matemática, isto é, não pode limitar-se às definições e conceitos matemáticos 'acabados', mas tem que ensinar de modo que os alunos vão 'construindo' esses conceitos com compreensão". Por consequência, como não se ensina o que não se sabe, o conhecimento didático acaba por não ser desenvolvido também pelo professor.

Analisando o processo de como se desenvolveu esta dinâmica, em diálogo com o grande grupo, há expressões referentes à percepção do desenvolvimento dos alunos e mudanças de perspectivas de ensino, sendo estas conquistas atribuídas ao PNAIC por pelo menos $62,5 \%$ das professoras. Como exemplo, apresenta-se a resposta dada pela professora $P 16$, logo após compartilhar sua satisfação em verificar a capacidade de seus alunos, no quarto encontro de formação:

Eu trabalhei muito gráfico com eles e o gráfico sempre já era pronto, para visualização. Não era algo que eles tinham que partir para construir. Então daí que eu achei que eles poderiam sentir dificuldade. Daí foi minha surpresa, eles não tiveram. Assim, quando eu fui construir o gráfico [...]. A gente primeiro fez a pesquisa em sala e foi feito as anotações no quadro. A partir dali foi criado um gráfico (P16).

0 ato de pensar sobre a própria prática aponta para os pressupostos da reflexão. Para Serrazina (2010), este é um elemento primordial na prática profissional docente:

0 objecto de reflexão é tudo o que se relaciona com a actuação do professor durante 0 acto educativo como, contexto, métodos, finalidades de ensino, conhecimentos e capacidades que os alunos estão a desenvolver, etc. Considera-se que a reflexão joga um papel central no desenvolvimento profissional dos professores pois à medida que aumentam os seus conhecimentos matemático e didáctico conseguem aprofundar a sua reflexão (SERRAZINA, 2010, p.10).

Em uma análise mais geral, quando perguntado, por meio de questionário, se houve mudança na forma do tacto pedagógico (Nóvoa, 2009), as professoras responderam que sim, com exceção de uma. Dos textos (não identificados, conforme proposta do questionário), destacam-se as seguintes opiniões: "Acredito que a formação trouxe uma oportunidade de melhorar minha prática, que era 
deficitária. Hoje sou uma professora que aprendeu a trabalhar (professor A2"); "Eu já tinha o hábito de trabalhar através do lúdico. 0 curso contribuiu ao sugerir novos meios de trabalhar, novos jogos, através da troca de experiência entre os professores ${ }^{3}$ (professor B)".

0 tacto pedagógico também foi analisado em outra pergunta apresentada nos questionários, tanto no diagnóstico como no de avaliação, sobre os recursos empregados para ensinar matemática, apresentados no gráfico 2.

Gráfico 2 - Gráfico Comparativo dos Recursos Empregados para Ensinar Matemática pelos Professores Alfabetizadores (PONTA GROSSA/ PR, 2014)

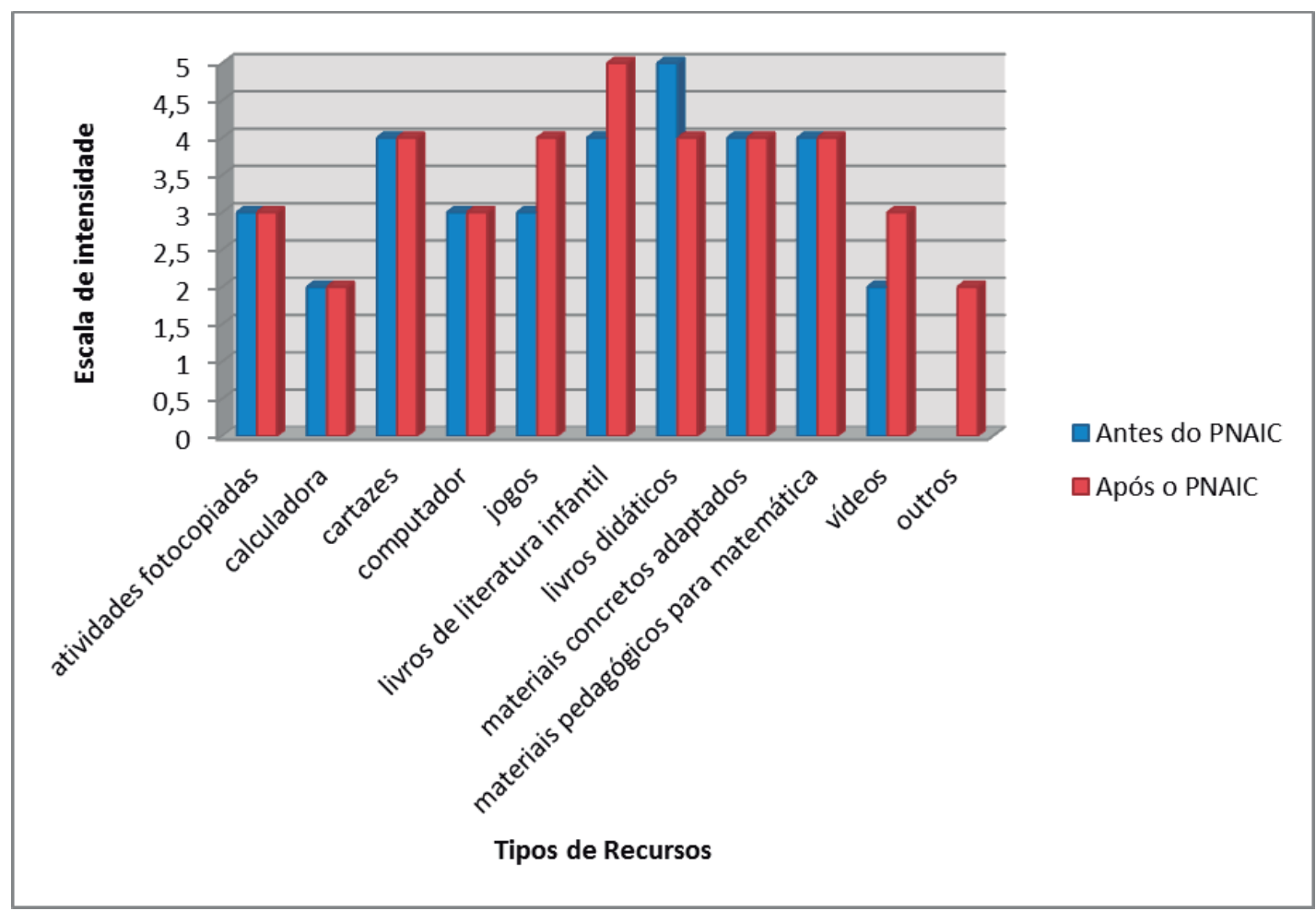

Fonte: A autora.

A cada recurso, foi solicitado ao professor indicar a intensidade do uso, em uma escala de 1 a 5 , sendo 5 usado com muita frequência e 1 nunca usado. Das respotas, foi realizada uma média do valor atribuído a cada item apontado na questão.

0 gráfico mostra uma sensível mudança na inserção do ensino de matemática aliado à literatura infantil e vídeos, como também no uso de jogos, focos da formação. Percebe-se também uma diminuição no recurso do livro didático. Sobre esse fato, Ponte e Serrazina $(2004$, p.6) recordam que até certo tempo, "o material considerado necessário para o ensino-aprendizagem da Matemática era o quadro e giz e o manual escolar". Porém, atualmente, reconhece-se por meio das pesquisas na área da educação matemática a importância de materiais concretos para a aprendizagem, de modo especial para o período de alfabetização, o que continua sendo empregado, porém, não como principal método.

2 Como não houve identificação nos questionários, os professores serão indicados pelas letras do alfabeto.

3 Resposta da professora que marcou que não houve mudança na forma como ensina matemática aos seus alunos após o PNAIC. 
Além dos questionários, foi possível dialogar com os sujeitos pesquisados sobre a prática pedagógica, voltada ao ensino de matemática. Entre as contribuições do PNAIC para sua prática de sala de aula, foram indicados, por meio das entrevistas: maior interesse dos alunos pelas atividades, devido ao trato lúdico (P11); busca na mudança de postura tradicional que assumiam (P01, P07 e $P 16)$ e satisfação do professor em verificar os avanços na aprendizagem dos alunos (P14 e P12).

Nesse aspecto, Serrazina (2010) faz uma interessante consideração, que vem ao encontro dos discursos dos professores, sobre como a conquista da confiança no próprio trabalho é construída ao passo em que se aprofunda o conhecimento matemático e 0 conhecimento didático matemático. A autora também reconhece que essa autoconfiança restabelece novas posturas do professor frente ao encaminhamento da prática pedagógica.

A autoconfiança e segurança na concretização da ação docente, aliada a práticas com significado para a infância, podem ser indicativos de uma das contribuições da formação continuada promovida pelo PNAIC.

Porém, houve indícios de que apenas a formação não seria suficiente para uma transformação. Em vários momentos, houve referências ao número elevado de alunos por turma (P06 e P10) e da falta de apoio a alunos com dificuldades ou distúrbios de aprendizagem (P06). Em dois casos se reconhecem alguma inserção de práticas diferenciadas, mas não caracterizadas como uma mudança (P03 e P10).

Neste sentido, analisa-se a capacidade reflexiva dos docentes, frente à sua prática pedagógica. Com base em García (1995), a reflexão e sua aplicação à formação de professores se materializa em pelo menos quatro formas (pela introspecção, pelo exame, pela indagação e pela espontaneidade), busca-se identificar nos momentos de diálogo com os professores qual é a profundidade da reflexão acerca da prática pedagógica.

Por meio das informações coletadas, verificam-se inicialmente discursos no universo da introspecção, explicado por García (1995, p. 64) como "reflexão interiorizada, pessoal, mediante a qual 0 professor considera os seus pensamentos e sentimentos numa perspectiva distanciada relativamente à atividade diária e quotidiana". Ao longo do processo de formação, percebem-se asserções que denotam reflexões pelo exame. Apesar de 0 trabalho estar motivado, ainda mais quando se percebe a aprendizagem dos alunos, não há características ainda presentes em um compromisso para uma mudança mais profunda, com caráter de transformação.

\section{O PLANEJAMENTO PARA O ENSINO DE MATEMÁTICA DOS PROFESSORES DE ANOS INICIAIS}

Os princípios que baseiam os planejamentos mostram traços importantes sobre a prática pedagógica. Considerando as afirmações de Sacristán e Goméz (1998, p. 279), entende-se que o planejamento tornou-se um dos pontos de análise a partir do momento em que passou a sofrer efeitos do PNAIC: "Dedicar tempo de trabalho a esta atividade, assisti-la com meios, centrar nelas programas de formação em exercício, oferecer recursos e exemplos, são formas de melhorar uma faceta profissional que tem incidência no desenvolvimento do ensino".

Os dados coletados foram passíveis de uma análise nas seguintes dimensões: o que falam os professores sobre o planejamento; como os professores registram seus planejamentos e como 0 PNAIC orientou e acompanhou o processo de planejamento. 
Na primeira dimensão, quando questionados onde procuram recursos para elaboração dos seus planejamentos, os professores apresentaram as seguintes informações, antes e após a formação do PNAIC, representadas no gráfico 3:

Gráfico 3 - Comparativo das Fontes de Consulta para Elaboração de Planejamento pelos Professores Alfabetizadores (PONTA GROSSA/PR, 2014)

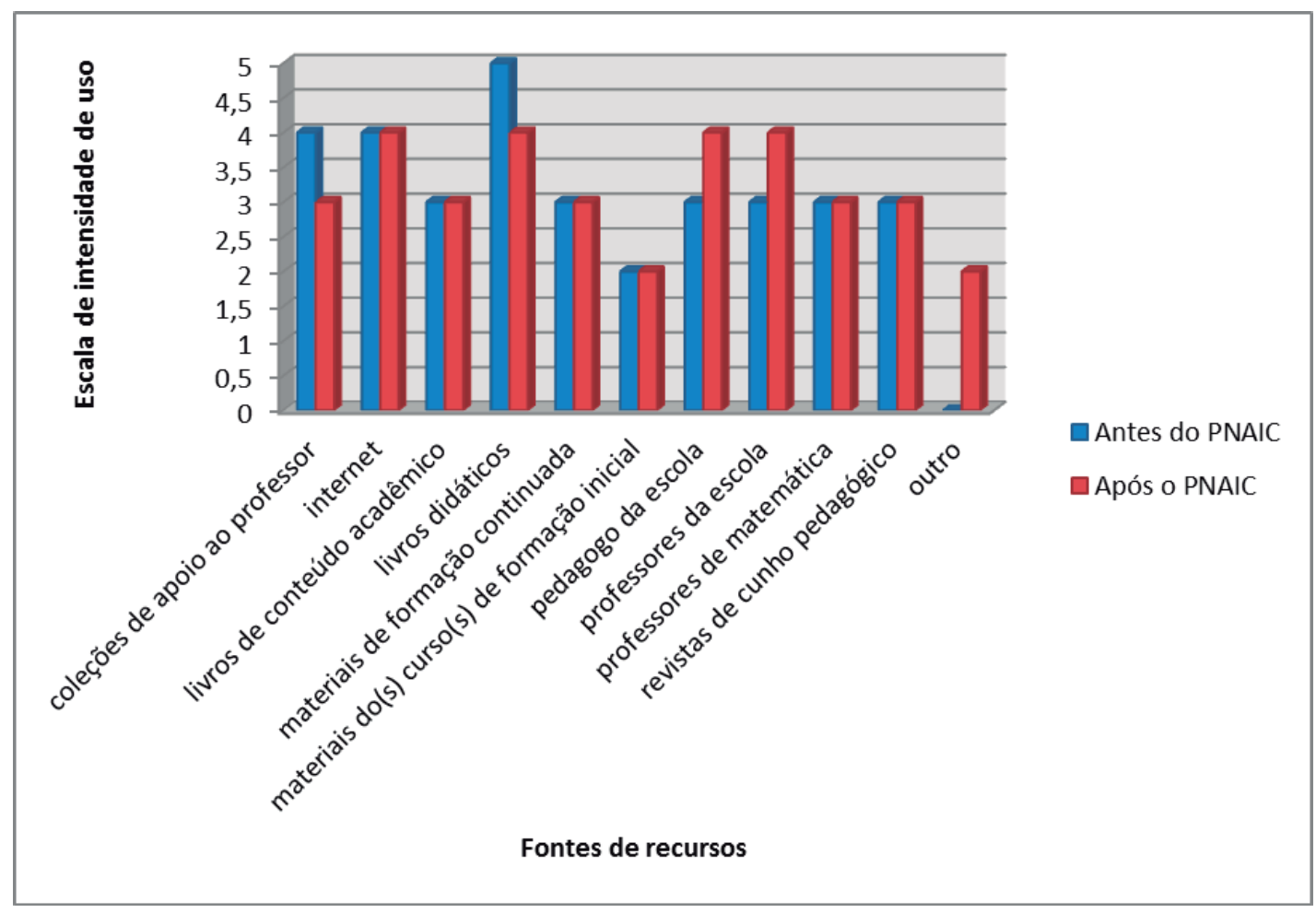

Fonte: A autora.

0 gráfico 3 mostra que os professores pesquisados baseavam seus planejamentos principalmente nos livros didáticos, coleções de apoio ao professor, que podem ser considerados na mesma linha do livro didático, e na internet. Após a formação, os docentes mostraram recorrer mais à equipe pedagógica da escola e a outros professores, o que nos indica maior trabalho coletivo realizado na escola. Os livros didáticos mais uma vez foram superados, pois eram usados como um dos principais recursos para ensinar matemática.

As professoras P06, P09, $P 15$ e $P 13$, que refletem $25 \%$ da amostra, relatam experiências de planejamento cooperativo em suas escolas.

Contudo, em entrevista, a professora P06 explica que esta ação, na verdade, é a divisão do planejamento entre as professoras, sendo que a cada semana, uma fica incumbida de realizá-lo. 0 motivo dessa prática recorre do cerceamento da hora atividade das docentes, oriundo da falta de profissionais na escola. Tardif e Lessard (2011) criticam a cultura de fragmentação do trabalho do professor, ressaltando que essa situação está presente na organização tanto do ambiente físico como no denominado "ambiente intelectual" (TARDIF; LESSARD, 2011, p. 87) do professor, tendenciando para formas de divisão de trabalho, indo na contramão de um trabalho cooperativo. 
Para compreender a importância de se planejar, momento do pensar sobre a aula, Serrazina (2012) explica que o professor expressa também concepções acerca do processo de ensinar e de aprender, refletindo seus saberes de formação profissional, disciplinares, curriculares e experienciais, conforme a classificação de Tardif (2012).

Um aspecto relevante foi quanto à seleção dos conteúdos a serem ensinados, considerando a proposta curricular. Nesta situação, a professora P07 afirma: "Não trabalhava muito jogos e com gráficos também não. E foi lá no Pacto que surgiu o entusiasmo em trabalhar com jogos, com gráfico, tanto que as crianças falaram que hoje está boa, a aula está diferente [...]". Essa informação remete ao comentário de Sarti (2012) sobre como a insegurança do docente influencia na abordagem do que ele ensina, retratado na prática da professora P07, a qual, antes de aprender na formação do PNAIC sobre gráficos, não desenvolvia plenamente esse conteúdo com suas turmas de alfabetização. Sobre o tema, a entrevista da professora $P 03$ também traz evidências sobre a fragilidade na concretização do currículo. Foi perguntado à professora o que norteia a seleção dos conteúdos, obtendo-se como resposta:

Só o tema, a gente tem o tema e daí você avança até onde você acha que pode ir, até onde que eu acho que sim. E daí, depende muito. Assim, tem turmas que vão além, tem umas que não,[...]. No meu ponto de vista, eu acredito que teria que ter, sabe, para que todas tentassem chegar naquele caminho. Nem todas vão chegar, a gente sabe que não chegam, mas para chegar o mais próximo possível, para que não haja isso que está acontecendo agora [...].

Essas falas alertam para uma premissa importante, talvez não levada em consideração nas discussões do PNAIC de forma efetiva, que é a gestão do currículo.

É evidente que para conhecer o currículo é preciso ir muito além das declarações, da retórica, dos documentos, ou seja, ficar muito mais próximo da realidade. 0 que se torna evidente é que, pelas propostas do currículo, expressam-se mais os desejos do que as realidades. Sem entender as interações entre ambos os aspectos não poderemos compreender 0 que acontece realmente aos alunos/as e o que aprendem (SACRISTÁN; GÓMEZ, 1998, p. 137).

Para Tardif (2012, p. 207), "os programas exercem, portanto, um papel importante, unificando a ação coletiva dos professores e orientando-a para os conteúdos e objetivos comuns. Eles permitem atingir padrões comuns e gerais". Essa asserção traz de forma clara a coerência sobre a inquietação relatada pela professora. Assim, compreende-se que aos docentes ainda não havia inteligibilidade, talvez pela falta do diálogo acerca dessa temática, da efetivação do currículo entendida como saber social e, por isso, deve ser elemento de partilha por todos os agentes educacionais (TARDIF, 2012).

Para verificar a segunda dimensão desta subcategoria, com relação aos registros de planejamento, buscou-se analisar a forma de organização da prática docente por meio dos planejamentos das professoras. Nesta etapa, quatro professores não disponibilizaram seus planejamentos, mais duas encontravam-se afastadas de suas atividades laborais. Portanto, foram analisados os planejamentos dos docentes P01, P03, P06, P07, P09, P10, P11, P12, P13 e P16, sendo possível indicar algumas considerações.

Com exceção de um caso, de P16, os planejamentos docentes mostram mudança na prática dos professores com a formação do PNAIC. 
Essa constatação ficou mais evidente quando se verificou a existência de equilíbrio na forma como as professoras passam a disponibilizar o tempo de trabalho para alfabetização da língua portuguesa e de matemática. Também, percebe-se que com o decorrer dos encontros de formação, os planejamentos começam a inserir situações problema, conforme orientações do programa de formação.

Como exemplo, na análise do planejamento de $P 11$, a média de distribuição de atividades no mês de março era de 79\% com comandos descontextualizados, tais como "Resolva", "Adição", "Subtração", "Resolva as operações". Ao final do mês de junho, essa média cai para 32\%, sendo grande parte das atividades envolvendo problemas de matemática. Já os planejamentos das professoras $P 01$ e P10, além desse resultado, é notável a integração do ensino de português e matemática, pois empregaram atividades a partir de um tema.

Sacristán e Gómez (1998) consideram que quando elaborado de forma consciente, o planejamento se torna um importante instrumento de reflexão, pois possibilita orientar a prática pedagógica futura, em um movimento de se pensar sobre ela. Assim, os autores indicam que 0 ato de planejar pode ser considerado um "processo de resolução de problemas" (SACRISTÁN; GÓMEZ, 1998, p. 276) a partir das problematizações que se evidenciam e a tomada de decisão frente a elas.

Porém, há casos, como no planejamento da professora P03, em que se percebe que a matemática é trabalhada periodicamente. Contudo, as atividades geralmente são direcionadas por comandos como: "Resolva as operações", "Resolva", "Resolva as subtrações", "Vamos subtrair", "Como lemos", "Subtração", "Como se lê" "Adição", sendo registrada pouca abordagem do trabalho com resolução de problemas, cerca de $36 \%$ dos exercícios, não havendo elevação dessa porcentagem, apesar de se tratar de uma turma de $3^{\circ}$ ano. Além disso, os planejamentos, salvo de $P 01$ e $P 10$, não trazem propostas interdisciplinares, com exceção do planejamento das atividades propostas pelo PNAIC.

Nos casos analisados, percebe-se 0 início de um enfrentamento dos dilemas da prática pedagógica, porém ainda de forma incipiente, pois apesar de demonstrarem mudança na forma de planejar, ainda não é clara a preocupação com a explicitação do que e para que se aprende (SERRAZINA, 2012). Entende-se a importância de atividades que orientem para o raciocínio e 0 uso do algoritmo, porém, essas propostas poderiam ser advindas, inicialmente, de um contexto, e não estarem baseadas no treino.

Analisando as orientações sobre o planejamento que emanaram do PNAIC, terceira dimensão desta subcategoria, após o desenvolvimento dos temas em cada encontro, os professores eram desafiados a planejar e aplicar uma atividade. Algumas atividades eram orientadas conforme os Cadernos do PNAIC e outras adaptadas pelo orientador. As propostas eram planejadas e aplicadas pelas professoras, sendo os resultados apresentados e discutidos pelo grupo no encontro posterior e registrados em um portfólio.

Porém, uma fragilidade encontrada foi a falta de acompanhamento do planejamento do professor. Nos encontros, os professores recebiam orientações do que precisariam desenvolver com seus alunos, sendo suas produções compartilhadas após a aplicação. Contudo, não havia um momento de reflexão sobre o planejamento proporcionado pelo curso, o que seria de grande relevância, conforme indica Serrazina (2012).

Na pesquisa realizada por Souza (2014, p. 425), quando analisa o Programa Pró-Letramento (Matemática), é criticada a forma como foi desconsiderado o momento de reflexão do planejamento.

No programa brasileiro, nota-se que o mesmo foi pensado nas universidades, porém, não houve uma efetiva aproximação no sentido de uma articulação entre os dois tipos de conhecimento: os produzidos pelas universidades e os desenvolvidos 
pelos professores em sua prática cotidiana. Nesse sentido, é possível inferir que fica sob a responsabilidade do cursista a aplicação, socialização, bem como uma espécie de tradução desses conhecimentos na sala de aula. Logo, tem-se então uma espécie de "treinamento de professores", que se subentende que seja suficiente para construção de um processo educativo transformador [...]

Os dados possibilitam perceber que a mesma fragilidade permeou o PNAIC, quando a proposta de formação presumia uma aplicação de técnicas sem antever uma reflexão sobre tais pressupostos. Essa falta de reflexividade replica falhas já ocorridas em processos formativos, denunciadas por Herneck e Mizukami (2002), Brzezinski (2008), Nóvoa (2009), Imbérnon (2011) e Sarti (2012), quando não se direciona um olhar crítico à realidade na qual se encontra e, por meio do diálogo, construir bases que permearão o processo educativo.

Somado a esses itens, a falta de articulação com a escola, de forma a não reconhecer que a mudança requer um esforço coletivo, acabaram por deixar o professor na atuação de sua prática docente, considerando as problemáticas de nível micro (NÓVOA, 1992).

Portanto, ao retomar as afirmativas de Curi (2005), quando explica sobre os requisitos necessários ao docente para ensinar matemática nos Anos Iniciais, entende-se que a atuação do professor deve se basear em alguns pontos importantes, tais como: objetivos de aprendizagem; seleção dos conteúdos a serem ensinados; previsão da organização do espaço da sala de aula; método de ensino; recursos a serem empregados e processo de avaliação. A formação do PNAIC acabou por focar apenas em três desses pontos: seleção de conteúdos, métodos de ensino e recursos. Assim, é possível que as contribuições do PNAIC na prática acabaram cerceadas pelo fato de não se aprofundar na reflexão acerca da importância do planejar e do acompanhamento desse processo.

\section{CONSIDERAÇÕES FINAIS}

Para retomar o foco central, motivador desta pesquisa, recorre-se ao problema inicial, delineado a partir da busca em conhecer quais contribuições da formação continuada em matemática do PNAIC para a prática pedagógica dos professores alfabetizadores, o que possibilitou alguns desvelamentos sobre este importante fenômeno que atingiu os alfabetizadores das escolas públicas de todo o Brasil.

Alguns autores da área de educação problematizam a formação do professor polivalente, considerando a ampla atuação que lhe é exigida, situação esta confirmada ao se verificar empiricamente o efêmero preparo do professor para ensinar matemática. Frutos de uma escolarização básica frágil, grande parte dos professores não conseguiu superar as lacunas de sua formação. Esta constatação foi a justificativa de implantação de frentes de formação continuada de professores alfabetizadores, entre elas, destaca-se aqui o PNAIC.

Assim, na busca em se verificar se o PNAIC interferiu na formação profissional do professor para 0 ensino de matemática, reconhece-se os avanços que o PNAIC possibilitou, permitindo 0 desenvolvimento de saberes disciplinares e curriculares, ao passo em que se valorizou o saber experiencial do professor.

Somando a isso, a reflexão sobre questões voltadas ao ensino de matemática, a inserção do lúdico e 0 emprego do método de resolução de problemas, foi possível perceber quanto a formação agregou à prática docente mais segurança em planejar estratégias diferenciadas para 0 alcance do aprendizado dos alunos. 
Nos relatos dos professores foi constatado que, ao perceber a satisfação dos alunos em realizar as atividades propostas, com empenho e de forma motivada, os professores despertaram o interesse em inserir o lúdico em suas práticas e atuar em áreas anteriormente pouco exploradas, como é 0 caso da resolução de problemas e do tratamento de informações. Porém, há de se salientar que as práticas, propostas como forma de aplicação do curso, estimularam apenas o compartilhamento dos resultados, deixando de valorizar o rico e importante momento do planejar.

Com isso, não houve momentos de reflexão que propiciassem a discussão e, por consequência, a formação, pensada de forma coletiva entre os professores participantes do curso, em torno das possibilidades de construção conjunta. A troca de experiências, tão valorizada pelas professoras participantes do curso, restringiu-se a relatos da prática já efetuada, servindo como uma espécie de coletânea de atividades compartilhadas.

Essa fragilidade ocorre como consequência da ênfase dada aos resultados finais, e não aos processos. Notadamente, tratou-se como desimportante 0 ato de planejar, 0 qual presume se partir dos objetivos a serem alcançados para então a seleção dos assuntos e métodos adequados, conforme os princípios da didática básica. Pelas atividades partilhadas pelos professores, observou-se a ênfase dada ao método.

Diante das situações identificadas, questiona-se como se poderia, conforme propõe o compromisso do PNAIC, promover a alfabetização de todas as crianças até os 08 (oito) anos de idade? Seria então 0 problema da carência de aprendizagem culpa da formação precária recebida pelo professor de Anos Iniciais? E se sim, seria com a formação do PNAIC que todas as lacunas de conhecimentos disciplinares e curriculares dos docentes seriam supridas?

Considera-se que o problema não é o objetivo que se propõe. Conclui-se que a situação conflitante é como considerar os condicionantes que influenciam no insucesso escolar e como convergir para ações que resultem no alcance desse objetivo. Para tanto, identifica-se que a formação do PNAIC ainda possui potencial ativo para atingir os pontos que sua ação ainda não permeou.

Além disso, quando se propôs analisar quais as contribuições da formação continuada em matemática do PNAIC para a prática pedagógica dos professores alfabetizadores do município de Ponta Grossa, conclui-se que outros pontos não foram claramente explorados, os quais refletem nas práticas do ensino, entre essas, salienta-se as concepções acerca de currículo e planejamento. A falta de clareza sobre esses objetos inibem avanços, porque não permitem ao professor refletir sobre os condicionantes que afetam o processo de ensino e aprendizagem.

Portanto, ratifica-se que as frentes de formação precisam superar a relação teórico-prática e passem a inserir em suas pautas discussões que permeiem futuras ações coletivas, frutos de reflexão, as quais devem visar a objetivos comuns. Isso porque o problema da alfabetização está além do emprego de técnicas adequadas, pois isso seria facilmente superado com formações do tipo técnicas.

Mas se a formação não daria conta sozinha da superação das fragilidades da educação, poderia ser questionado o porquê então investir em formação continuada. Finaliza-se respondendo que: por meio da formação contínua, é possível refletir criticamente sobre a realidade dada; a reflexão crítica, acerca da realidade dada, é que promove transformações e, aí sim, pelas transformações, podemos mudar este cenário. 


\section{REFERÊNCIAS}

BRASIL. Portaria $n^{0}$ 867, de 4 de julho de 2012: Institui o Pacto Nacional pela Alfabetização na Idade Certa e as ações do pacto e define suas diretrizes gerais. Diário Oficial da União. Poder Executivo, Brasília, DF, 5 jul. 2012, seção 1, p. $22-23$.

BRZEZINSKI, Iria. Políticas contemporâneas de formação de professores para os anos iniciais do ensino fundamental. Educação \& Sociedade, Campinas, v. 29, n. 105, p. 1139-1166, set./dez. 2008.

CHANTRAINE-DEMALLY, L. Modelos de formação contínua e estratégias de mudança. In: NÓVOA, António (Coord.). Os professores e a sua formação. Dom Quixote: Lisboa, 1995

CUNHA, D. R. A matemática na formação de professores dos anos iniciais do ensino fundamental: relações entre a formação inicial e a prática pedagógica. 2010. 107 f. Dissertação (Mestrado em Educação em Ciências e Matemática) Faculdade de Física, Pontifícia Universidade Católica do Rio Grande do Sul, Porto Alegre, 2010.

CURI, E. Formação de professores polivalentes: uma análise de conhecimento para ensinar matemática e de crenças e atitudes que interferem na constituição desses conhecimentos. 2004. 278 f. Tese (Doutorado em Educação Matemática) - Pontifícia Universidade Católica de São Paulo, São Paulo, 2004.

GARCÍA, C. M. A formação de professores: novas perspectivas baseadas na investigação sobre o pensamento do professor. In: NÓVOA, António (Coord.). Os professores e a sua formação. Dom Quixote: Lisboa, 1995.

IMBERNÓN, F. Formação docente e profissional: forma-se para a mudança e a incerteza. 9. ed. São Paulo: Cortez, 2011.

MORAES, R.; GALIAZZI, M. C. Análise textual discursiva. ljuí: Ed. Inijuí, 2007.

NÓVOA, A. (Coord.). As organizações escolares em análise. Lisboa: Dom Quixote, 1992.

. Para uma formação de professores construída dentro da profissão. Revista de Educación, Madri, n. 350, 2009. Disponível em: https://bit.ly/3eZBCJe. Acesso em 12 abr. 2015

PASSOS, C. L. B. et al. Desenvolvimento profissional do professor que ensina matemática: uma meta-análise de estudos brasileiros. Quadrante, Lisboa, v. 15, n. 1 e 2, 2006.

PONTE, J. P.; SERRAZINA, L. Práticas profissionais dos professores de matemática. Quadrante, Lisboa, v. 13, n. 2 , p. 51-74, 2004.

SACRISTÁN, J. G.; GÓMEZ, P. A.I. Compreender e transformar o ensino. $4^{0}$ ed. São Paulo: Artmed, 1998.

SARTI, F. M. 0 triângulo da formação docente: seus jogadores e configurações. Educação e Pesquisa, São Paulo, v. 38, n. 2, p. 323-338, 2012.

SERRAZINA, M. L. A formação contínua de professores em matemática: o conhecimento e a sua supervisão em sala de aula e a sua influência na alteração das práticas. International Journal for Studies in Mathematics Education, Hendek/Sakarya, v. 2, n. 2, p. 1-23, 2010. 
Conhecimento matemático para ensinar: papel da planificação e da reflexão na formação de professores.

Revista Eletrônica de Educação, São Carlos, v. 6, n. 1, p 266-283, mai. 2012.

TARDIF, M. Saberes docentes e formação profissional. Petrópolis: Vozes, 2012.

. LESSARD, C. 0 trabalho docente: elementos para uma teoria da docência como profissão e interações humanas. Tradução: João Batista Kreuch. 6. ed. Petrópolis: Vozes, 2011.

YIN, R. K. Estudo de caso: planejamento e métodos. 2. ed. Porto Alegre: Bookman, 2001.

RECEBIDO EM: 11 JUN. 2019

CONCLUÍDO EM: 28.09.2019 
